Article

\title{
Non-Destructive Evaluation of Closure Joints in Accelerated Bridge Construction using a Damage Etiology Approach
}

\author{
Saman Farhangdoust*(D) and Armin Mehrabi (D) \\ Accelerated Bridge Construction University Transportation Center (ABC-UTC), Department of Civil and \\ Environmental Engineering, Florida International University, Miami, FL 33174, USA; AMehrabi@FIU.edu \\ * Correspondence: Sfarh006@fiu.edu
}

Received: 7 December 2019; Accepted: 6 February 2020; Published: 21 February 2020

\begin{abstract}
In accelerated bridge construction (ABC), prefabricated bridge deck elements are merged using "closure joints." Because of the cast-in-place nature of closure joints that are expected to go into service rapidly and problems observed for some types of closure joints, there have been some concerns about their long-term durability. This has necessitated the need for monitoring the condition of $\mathrm{ABC}$ closure joints using non-destructive testing (NDT) methods. Closure joints contain unique features and details that sets them apart from conventional deck panels. This requires a special treatment of closure joints when it comes to selecting the appropriate NDT technique for their health monitoring. A clear guideline for selecting an applicable NDT method for various types of closure joints has not been developed yet. For this purpose, an investigation was carried out in the Accelerated Bridge Construction University Transportation Center (ABC-UTC) at Florida International University. This paper summarizes the result of this investigation. It includes reviews of all relevant NDT methods for applicability to $\mathrm{ABC}$ closure joints and efforts for categorizing closure joints according to joint features that affect the use of NDT. Since the applicability of NDT methods heavily depend on the type of expected anomaly to be detected and its root causes, all potential defects and types of damage were identified and investigated using a damage sequence tree (DST). Consequently, damage etiology for $\mathrm{ABC}$ closure joints were established using fault tree analysis (FTA). Finally, a quantitative statistical survey was used to substantiate the selection of the NDT methods that were most applicable to the health monitoring of $\mathrm{ABC}$ bridges containing closure joints. The results presented in this paper can be used by bridge owners and consultants as an effective and practical guide for the selection of NDT methods for monitoring the health of ABC closure joints.
\end{abstract}

Keywords: damage etiology; damage detection; structural health monitoring; non-destructive testing; accelerated bridge construction; closure joints; bridge inspection; concrete deck

\section{Introduction}

The application of accelerated bridge construction (ABC) to the designing, planning, and construction of bridges organizes construction activities in such a way that reduces on-site construction activities, as well as saves maintenance costs during its service life. This method heavily depends on the use of prefabricated elements that are put together near or off-site, and then transported to the bridge location for installation (Figure 1) [1,2]. 

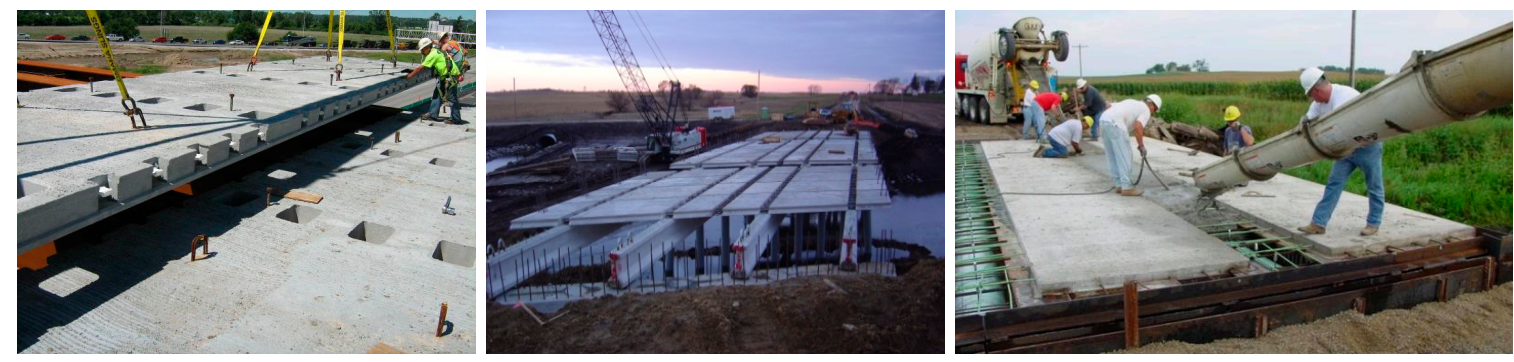

Figure 1. Examples of an accelerated bridge construction (ABC) process (Used with permission by Iowa DOT) [3].

The ABC methodology addresses some of the main disadvantages of the conventional bridge construction techniques, such as the delay in casting and curing of concrete elements, which requires construction in sequence; traffic interruptions; safety issues; and dependency on the weather. $A B C$ implementations also enhances safety for the public and workers. In the $A B C$ method, although elements are normally prefabricated/precast in the precast plants and shops, the elements need to be put together and made integral with the use of joints that are cast in place. There are various types of joints that connect different segments of the bridge. Those joining the deck elements are commonly called "closure joints" [2]. Since the ABC deck is expected to be drivable quickly, the quality of cast in situ joints is a matter of concern. The joint quality is controlled by the quality of the concrete, steel reinforcement, and steel embedment. The quality of concrete is influenced by the procedure used for casting and curing. It is also realized that the presence of reinforcing bars and enclosures can create congestion within the joint. Therefore, there is a potential for defects to be left in place during construction or appear later. The presence of a cold joint, incompatibility of the material, or obstructions created by steel embedment and potential for voids only increase the possibility of such anomalies, creating a higher potential for exposure and degradation in time [1]. Because of this, a weak link may be created in the bridge structures. Hence, the durability of ABC closure joints has been a matter of discussions. If damage and defects are not detected early in the life of the bridge and degradation advances, major repair and rehabilitation efforts will be required for maintenance of the bridge. This is in strong contrast with the notion of $A B C$ since it defeats the very purpose of less interruption to traffic. The most common types of damage observed in concrete decks (and specifically in deck joints) are known to include one or more of: voids and honeycombing, cracking, delamination, loss of cross-section for embedded bars due to corrosion, spalling of concrete due to steel corrosion, leakage of surface water through joints and cracks, roughness, and the abnormal appearance of concrete surfaces. Non-destructive testing (NDT) has been used mostly for local damage detection, as well as in some case for the detection of damage globally in engineering structures, including bridges [4]. Although a variety of NDT techniques have been employed for bridges with concrete elements with or without joints, a unified selection guide for NDT methods with a focus on the closure joints is lacking.

To address this shortcoming, past evaluations of the performance of the closure joints and inspection results were used in this paper to identify potential damage and their sequence in relation with closure joints, and development of a practical damage sequence tree (DST). This provides a novelty in the approach to the selection of NDT methods with the highest applicability to evaluating and identifying the damage related to $\mathrm{ABC}$ closure joints. It also aims to provide an association between defects and their causes in the form of damage etiology. Damage etiology provides a great help for the selection of NDT methods that best serve the purpose of health monitoring of the closure joints. These processes are also incorporated into a fault tree analysis (FTA) to assist in effective and accurate decision-making regarding selection of the most applicable NDT methods.

At the same time, NDT methods utilized for bridge inspections reported in numerous publications were evaluated to identify methods with a better potential for use in the health monitoring of $A B C$ closure joints. A comprehensive investigation was carried out in relation to the limitations and 
capabilities of various methods, and consequently, the promising methods were compared and evaluated based on their applicability to damage detection in closure joints. This investigation was carried out in accordance with an established set of criteria taking into account the type of defects. The results are then analyzed through DST and FTA to construct a guide framework that can be practically used to identify the NDT methods most appropriate for the detection of specific defects associated with each type of closure joints. To substantiate the basic conclusions of these analyses with quantitative measures, a statistical survey was also performed on the applicability of NDT methods to defects and types of damage that are specific to closure joints. This paper is organized such that its outcomes would allow for the compilation of procedures and guidelines for field implementation, methods of reporting, and inclusion within existing bridge inspection programs.

\section{Identification and Grouping of Deck Closure Joints}

In addition to other sources, this study used the results of a survey of state departments of transportation regarding common details and types of joints for prefabricated elements of the superstructure, substructure, and foundation of $A B C$ bridges that were included in a report by the US Federal Highway Administration (FHWA) [5]. The primary focus of this paper, however, is on the closure joint connection for concrete deck configurations. A large number of joint details were recognized as common deck joints [1]. Based on their overall configuration and features that would influence the use of specific NDT methods, these joint details were categorized into five distinctive groups/types. Table 1 shows these five categories of closure joints with their brief description. Reinforcing bars and post-tensioning ducts may be present in each of the ABC closure joints. These closure joints may have embedded steel elements other than reinforcing bars that are needed for installation processes. For the non-destructive evaluation (NDE) of each type of closure joint, the inclusion of bars and ducts will need to be accounted for to avoid false damage detection signals. Self-consolidating, fast-setting, high-early-strength concrete; non-shrink concrete; normal concrete; and high-performance and ultra-high-performance concrete (HPC and UHPC) types have been used in casting the $\mathrm{ABC}$ closure joints. Any other closure joints that could not be grouped in the aforementioned joint categories, if needed, can be investigated separately for the selection of the appropriate NDT method and its application process.

Table 1. Grouping of ABC closure Joints.

\begin{tabular}{|c|c|c|c|}
\hline Group & Brief Explanation & Symbol & $\begin{array}{c}\text { A View and } \\
\text { Cross-Section [1] }\end{array}$ \\
\hline Type 1 & $\begin{array}{l}\text { Usually for joining full-depth precast deck } \\
\text { panels, generally have diamond-shape } \\
\text { cavity for shear transfer. }\end{array}$ & & \\
\hline Type 2 & $\begin{array}{l}\text { Connecting full-depth precast deck panels } \\
\text { to each other, and precast decks to precast } \\
\text { concrete and steel girders. }\end{array}$ & & (1) \\
\hline
\end{tabular}


Table 1. Cont.

\begin{tabular}{|c|c|c|c|}
\hline Group & Brief Explanation & Symbol & $\begin{array}{c}\text { A View and } \\
\text { Cross-Section [1] }\end{array}$ \\
\hline Type 3 & $\begin{array}{l}\text { Refers to linear joints that connect partial } \\
\text { depth precast deck panels, butted decked } \\
\text { precast girders, and in some cases, precast } \\
\text { slab longitudinal connection to steel girders. }\end{array}$ & & \\
\hline Type 4 & $\begin{array}{l}\text { Has a V-shape cross section, used for } \\
\text { connecting two prestressed T-beams, and } \\
\text { sometimes full or partial depth deck panels. }\end{array}$ & & \\
\hline Type 5 & $\begin{array}{l}\text { Box-shaped joint, known as blockout, } \\
\text { connects steel girders or concrete I-beams to } \\
\text { precast full-depth deck panels. }\end{array}$ & $1\} 11$ & (n) \\
\hline
\end{tabular}

\section{Types of Defects in ABC Closure Joints}

$\mathrm{ABC}$ closure joints may contain different types of defects and anomalies. The type of defects and their causes are major factors when choosing the most applicable NDT techniques for non-destructive evaluation of the $A B C$ closure joints. Literature with a focus on defects and types of damage related to $\mathrm{ABC}$ closure joints are very limited; however, much can be learned from defects associated with the concrete deck in general. A review of the literature in this subject has recognized the following defects and types of damage that may apply to closure joints:

- Delamination (wearing surface)

- Reflective concrete cracking

- Internal cracks/discontinuities

- Debonding/separation at cold joints

- Delamination of the concrete cover

- Cracking/spalling of the concrete cover

- Internal voids

- Honeycombing

- Concrete segregation

- Surface roughness

- Surface defects

- Abnormal appearance

- Exposure of reinforcing bars and steel embedment

- Leakage through joints and cracks

- Corrosion of embedded steel plates or connectors (due to exposure or material contamination)

- Corrosion of reinforcing bars (due to exposure or material contamination)

- Cross-section loss or breakage of reinforcing bars, couplers, and other steel embedment.

Some of these types of damage are shown in Figure 2. These types of damage are, directly or indirectly, a result of factors such as material defects, design flaws, improper workmanship, and mechanical and environmental effects [6]. These types of damage, in turn, may result in the initiation of sequential damage within the closure joints at various stages. For example, shrinkage 
caused by the use of excessive water in the concrete mix can result in cracking at joint interfaces, which in turn would allow for leakage of water through cracks, and consequently, cause corrosion of the embedded steel. The corrosion of steel follows with a volume increase, therefore if left unchecked, it can in time cause cracking and spalling of concrete [1]. The spalling of concrete exposes the steel and makes it more vulnerable to a corrosive environment.

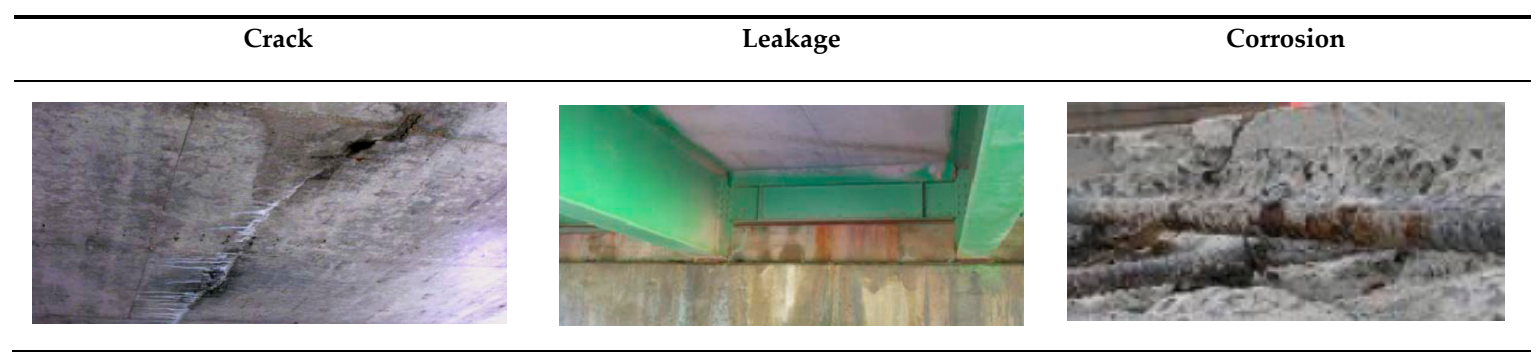

Figure 2. Some of the different types of damage of bridges (Used with permission by Iowa DOT) [7]

Workmanship issues are commonly mentioned as a potential cause for typical anomalies in ABC deck joints. As an example, honeycombing and voids are two typical defects in concrete structures that can be caused by improper mix design, and a substandard concrete mixing, placing, and curing process. One of the most detailed investigation on the evaluation of performance of the $A B C$ closure joints has been performed by the Utah Department of Transportation (UDOT) [8]. In their investigations, shrinkage cracks in blockouts have been reported after construction, pointing to the selection of an improper concrete mix as the major cause. Their report also mentioned bleeding of the excess water in concrete that contributed to an increase in shrinkage. In another case, shrinkage cracks in several blockouts were observed and the selection of the wrong construction materials was blamed as the major cause of the defect. Such causes are considered as mix design and workmanship issues in the etiology of defects in bridge closure joints, which are summarized later in the damage sequence tree (DST).

Other investigations have been conducted for the evaluation of different types of cracks in closure joints [9]. Reflective cracking is a type of crack that initiates from sharp corners and cold joints inside the deck. Longitudinal cracking along linear joints is another type of damage that causes leakage issues for closure joints. Leakage through joints and cracks itself becomes a cause for corrosion of the reinforcement within the closure joints. One of the first sources pertinent to damage in closure joints for side-by-side box-beam bridge superstructure is the work by Aktan et al. [10]. They concluded that longitudinal reflective cracking is prevalent among all side-by-side box-beam bridges, regardless of the age of the bridge constructions. For this type of bridge, cracks appear along the beam-shear key interface within two to three days after grouting the joints. These cracks were somehow closed after post-tensioning but were still visible. Additionally, they noted that at about 15 days after the deck placement, and often before the deck is subjected to a live load, reflective cracks appeared in the deck. The cause of cracking was inferred to be environmental and intrinsic loading, such as temperature variation and drying shrinkage. The cracking at the joints resulted in the leakage of water and the subsequent damages [10]. It is realized that $A B C$ superstructures, regardless of the type of closure joints, are prone to surface discontinuities and corrosion of the embedded reinforcement. It is also realized that each of the five groups of closure joints could be more vulnerable to one or more of the distinctive defects than the others. As an example, in a Type 1 closure joint, which is a linear joint with a diamond-shaped cross-section, a void in the cavity at the interior corners can be expected. A Type 2 closure joint, which connects the full-depth precast deck panels to each other, has more potential for developing cracking and debonding at cold joints, as well as leakage through the joints. Debonding and delamination at the cold joint area, as well as cracking and reflective cracking, can be expected in Type 3 closure joints, in which two dissimilar concrete layers form the deck thickness. A V-shaped Type 4 (or mechanical) closure joint, designed for connecting two pre-stressed tee beams or double 
beams by using connector plates at two sides of the joint, can be vulnerable to grout cracking, leakage, and corrosion of the embedded steel.

A damage sequence tree (DST) covering potential closure joint defects and types of damage at various levels was developed in this study and is illustrated in Figure 3. As shown in this figure, the DST attempts to make the connection between various recognized defects of $A B C$ closure joints and their main causes as the basis for a better understanding of an approach to bridge defect etiology. Following the path in the etiology of several types of damage in bridge decks and closure joints, in many cases, leads to the procession of damage from a smaller to larger scope, and more importantly, from one to another type and level of damage.

Therefore, a root cause may be a direct culprit for one type of damage, which if left unattended, can result in the occurrence of another type of damage (Figure 3). As a practical approach, DST can facilitate investigating the root cause of defects in closure joints for the structural health monitoring of bridges. This forms the basis for the new approach introduced in this paper for the health monitoring of $\mathrm{ABC}$ closure joints that combines a deep knowledge of features and vulnerabilities of the closure joints with the capabilities and potentials of various NDT methods for the detection of potential defects and types of damage. 


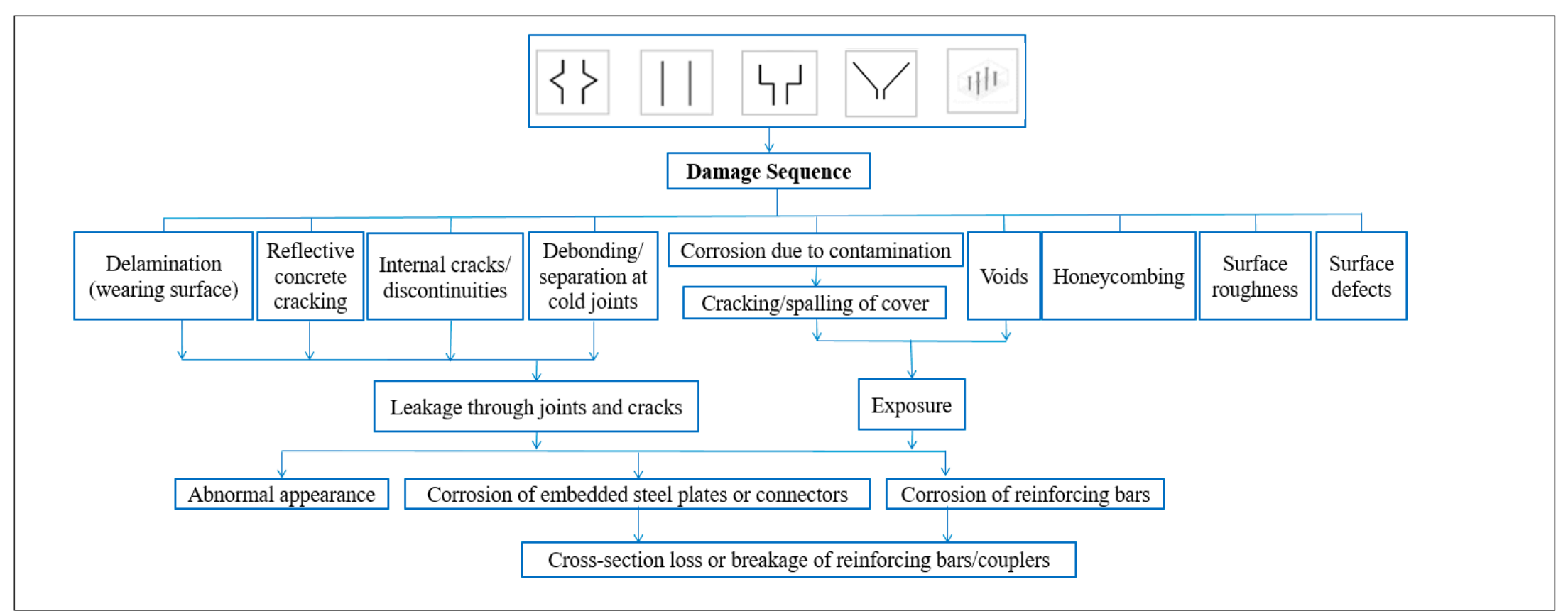

Figure 3. Damage sequence tree (DST) for ABC closure joints. 


\section{Bridge Damage Etiology Approach}

Understanding the etiology of types of damage is believed to facilitate damage detection in closure joints. Evaluation of the causes of defects in specific cases for bridge superstructure has been carried out in earlier investigations [11]. A cause-effect relationship for common types of damage in the deck joints has also been introduced by Mehrabi and Farhangdoust [1]. According to inspection observations, most of the defects mentioned above can be caused by one or more of the issues related to the design, material, workmanship, mechanical, and environmental effects. Damage etiology attempts to construct rational relationships between observed or presumed defects in $\mathrm{ABC}$ closure joints and their causes. It is also believed that the categorization of the type of the joints, their associated types of damage, and the FTA facilitate the proper selection of NDT methods and interpretation of their results, and provides for a new approach to health monitoring of the joints.

\subsection{Workmanship}

Observations from several investigations [12] reveal that workmanship perhaps plays the most significant role in many defects reported for closure joints. Workmanship errors can affect all aspects of closure joints, including forming, concrete mixing, casting, curing, pumping, steel fabrication, and installation. Error in material selection and procurement can also become a factor in the development of defects. Excessive shrinkage has been considered as a result of material and/or workmanship issues. This type of damage is the change in volume of concrete because of changes in moisture content or chemical changes. Shrinkage of restrained concrete is one of the main causes of cracking. This plays a significant role in the durability of closure joints, and is a likely cause for various types of cracks, delamination, and separation in ABC closure joints [13].

\subsection{Design Issues}

One significant factor regarding the occurrence of defects in deck joints is improper design and detailing. A design intended to provide for a certain function for the joint may cause complications in the implementation or performance of the joint for other aspects. Some design features in certain joint configurations has shown to result in the initiation and progression of specific types of damage. For example, shear-key, diamond-shaped joints may be susceptible to voids being left at their internal acute corners or develop reflective cracking initiated from the corners. The joints with sharp corners lead to stress concentration, which makes the joints more vulnerable to some defects [14].

\subsection{Material Deficiency}

Using deficient and substandard material for constructing an ABC closure joint can cause some typical defects, such as delamination, voids, and cracks. As an example, the type of aggregate can cause internal cracking or debonding. Also, chemical contaminants, such as chloride or sulfate in the cement material, can be the cause of accelerated corrosion of the embedded reinforcement and degradation of the concrete. Another important parameter is the concrete mix design. Improper mix design can lead to segregation, bleeding, and high porosity $[14,15]$.

\subsection{Mechanical Effects}

Mechanical parameters, such as live load effects, can be another cause for damage during the service life of $A B C$ closure joints. Abrasion and similar mechanical effects can also cause damage to the closure joints. Mechanical effects should therefore be considered when the etiology of defects is evaluated [16].

\subsection{Environmental Effects}

Another set of important parameters that cause defects, particularly in terms of surface defects, are environmental effects. Moisture, temperature variation, freeze and thaw, precipitation, exposure to 
salt and seawater, carbonation, and other environment factors can have detrimental effects on $A B C$ closure joints [17].

Figure 4 illustrates the relationships between common defects that are anticipated for $A B C$ closure joints and the most likely causes for those defects that include issues with the design and detailing, material, mechanical effects, workmanship, and environmental effects. Potential causes, including root causes, for damage and defects in ABC closure joints are illustrated in detail in Figure 5. The information in this figure, along with the cause-and-effect relationships shown in Figure 4, will allow for an effective fault tree analysis (FTA).

FTA can assist in the application of a proper NDT method and the health monitoring of closure joints. It is essential that the evaluation of distinctive $A B C$ closure joints is performed in relation with different types of defects/anomalies, as well as their causes. For example, a sign of water leakage or efflorescence on the underside of the deck can be traced to cracking, and therefore, will lead to the use of an NDT method(s) that is (are) capable of detecting cracks. The presence of cracks, in turn, may reference the FTA to find a cause or source that would indicate the potential for other types of damage associated with the same source and prompt the application of a specific NDT method. The NDT methods that are most applicable to each type of damage are identified through a quantitative statistical survey later in this paper. 


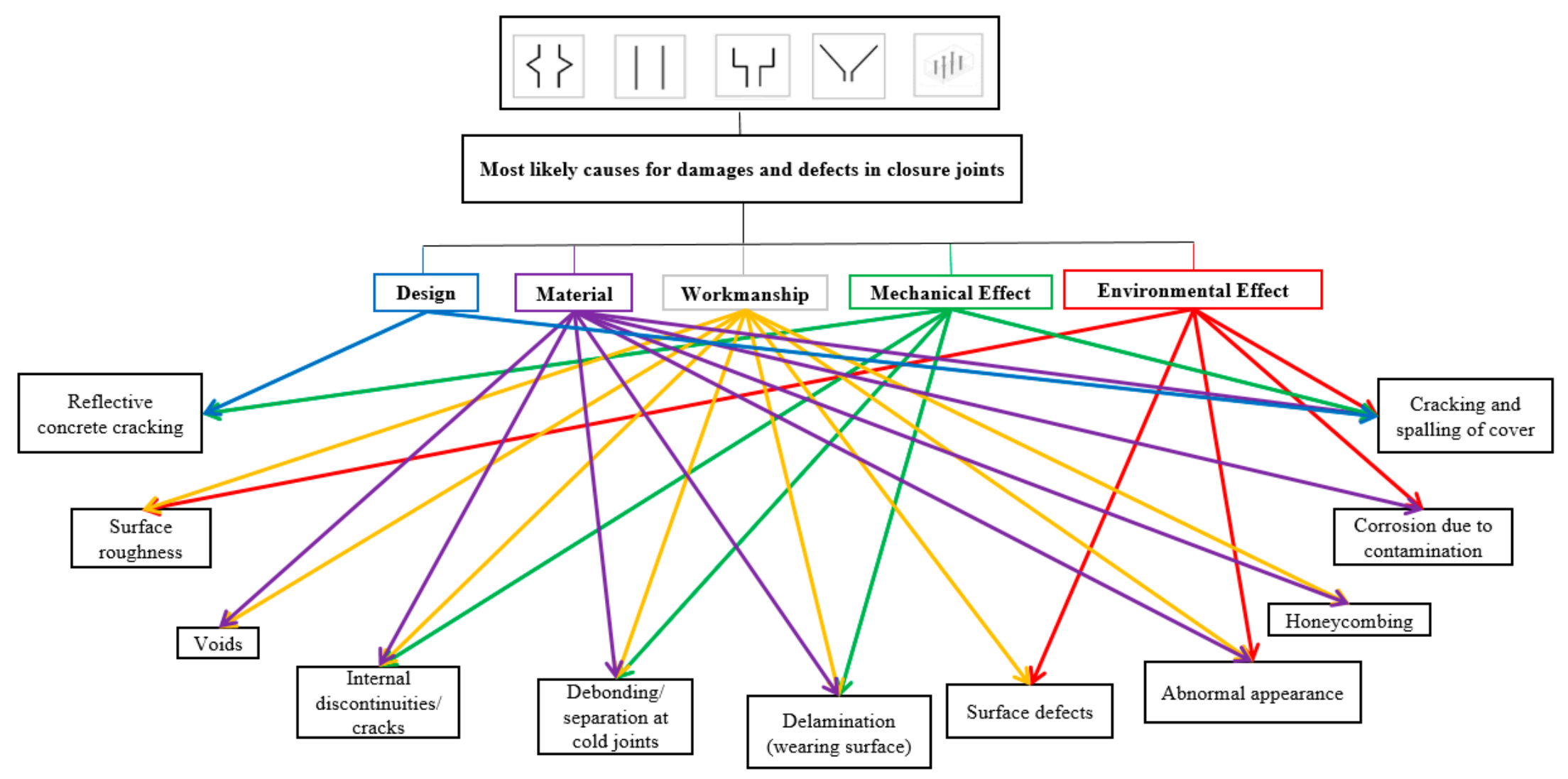

Figure 4. The most likely causes for damage and defects in $\mathrm{ABC}$ closure joints. 


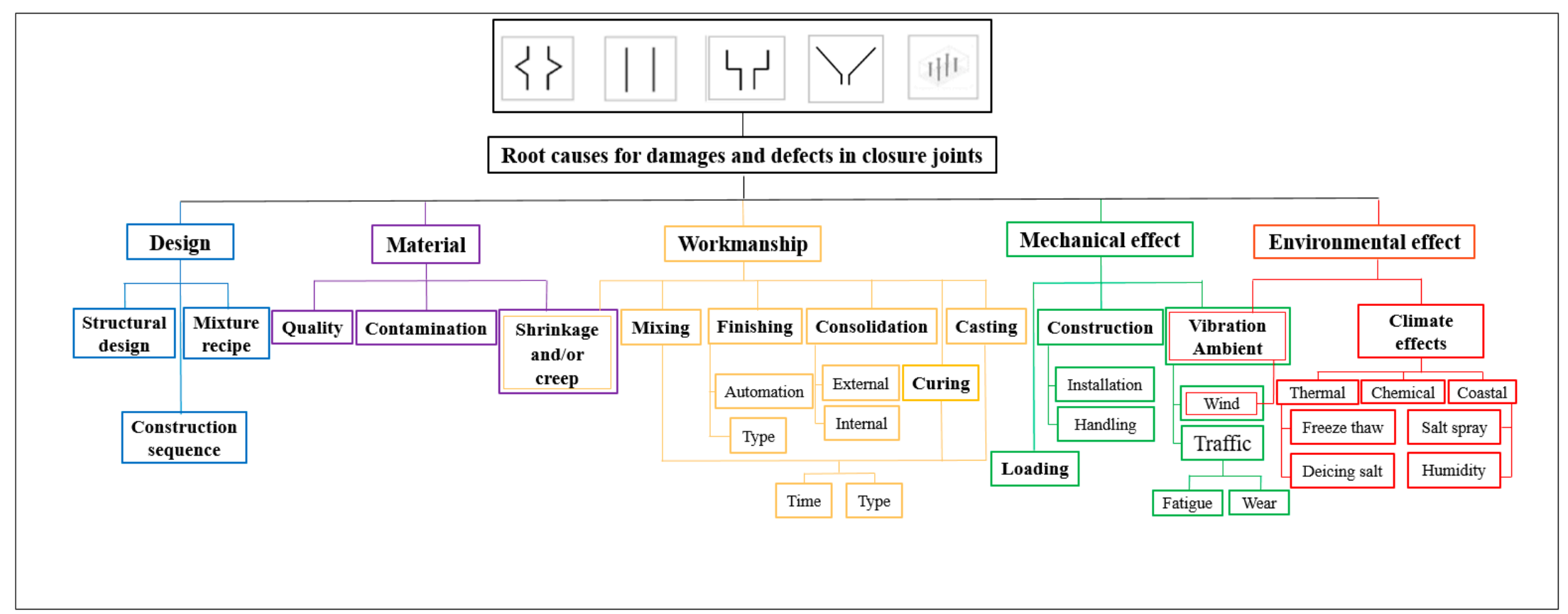

Figure 5. Root causes for damage and defects in $\mathrm{ABC}$ closure joints. 


\section{Applicability of NDT Methods to ABC Closure Joints}

This paper has emphasized the role of closure joints as potential weak links in ABC, and the need for accurate inspection of the closure joints as an essential part of the health monitoring of bridges built using the $\mathrm{ABC}$ method. This section compares several non-destructive techniques that are deemed potentially applicable to the inspection of $\mathrm{ABC}$ closure joints. A comprehensive review on several NDT methods with applicability to concrete decks (a total of 18 methods) has been performed by Farhangdoust and Mehrabi [18]. According to the evaluation of capabilities, among the techniques investigated, the following NDT methods were identified to have better potential for the monitoring of $\mathrm{ABC}$ closure joints [1]:

1. impact echo testing (IE)

2. radiographic testing $(\mathrm{RT})$

3. ground penetrating radar testing (GPR)

4. impulse response testing (IRT)

5. ultrasonic testing (UT), including phased array ultrasonic testing (PAU)

6. infrared thermography testing (IR)

7. magnetic flux leakage testing (MFL).

\subsection{Promising NDT Methods Comparison}

The selected methods were compared and rated, and the results are given in Table 2. The capabilities and attributes considered for rating the applicability of the methods used for $A B C$ closure joints include: test speed, internal detection (ability to detect internal defects), accuracy, analyzing speed, cost, ease of use, safety for public and operator, required operator skill, and repeatability [1]. As a result of the evaluation shown in Table 2, based on the number of Gs, Fs, and Ps, the top five ranked NDT methods were identified as being IE; GPR; UT including PAU; IR; and IRT. Electro-chemical testing (e.g., the electrical resistivity test and half-cell potential method) for corrosion detection, though effective in certain conditions, has not been included among the NDT techniques considered in this study.

Table 2. Qualitative comparison and preliminary rating of NDT methods for ABC closure joints:

\begin{tabular}{|c|c|c|c|c|c|c|c|}
\hline Capability & IE & GPR & UT & IR & IRT & RT & MFL \\
\hline Test Speed & F & G & F & G & $\mathbf{F}$ & $\mathbf{P}$ & $\mathbf{F}$ \\
\hline Internal Detection & G & G & G & $\mathbf{P}$ & $\mathbf{F}$ & G & $\mathbf{F}$ \\
\hline Analyzing Speed & F & $\mathbf{F}$ & F & G & $\mathbf{F}$ & G & $\mathbf{F}$ \\
\hline Cost & G & G & $\mathbf{F}$ & G & G & $\mathbf{P}$ & $\mathbf{P}$ \\
\hline Accuracy & G & $\mathbf{F}$ & G & F & $\mathbf{F}$ & G & $\mathbf{F}$ \\
\hline Ease of Use & G & G & G & G & G & $\mathbf{P}$ & $\mathbf{P}$ \\
\hline Safety for Public and Operator & G & G & G & G & G & $P$ & F \\
\hline Required Operator Skill & G & G & G & G & G & $\mathbf{P}$ & $\mathbf{P}$ \\
\hline Repeatability & G & $\mathbf{F}$ & G & $\mathbf{F}$ & $\mathbf{F}$ & G & $\mathbf{F}$ \\
\hline
\end{tabular}




\subsection{Grouping of Various Defects}

Furthermore, although the focus of this paper was on NDT methods that would be employed to detect damage that is not visible, it was realized that for visible damage and defects, visual inspection always offers the fastest, most economic, and most accurate method of detection. Hence, among the potential defects for closure joints described earlier in this paper, visible defects, such as an abnormal appearance including signs of leakage and efflorescence, surface defects, surface roughness, surface cracks, spalling of concrete cover, and exposure of reinforcing bars and embedment, can be best detected using visual inspection. The potential defects that are not visible can be listed as follows:

- delamination of wearing surface

- delamination of concrete cover (before cracking and spalling becomes visible)

- reflective cracks (for the extent of cracking inside the joint)

- $\quad$ voids (internal)

- honeycombing (internal)

- debonding at cold joints (for the extent inside the joint)

- concrete material segregation

- corrosion of reinforcing bars

- corrosion of embedded steel.

According to the bridge damage etiology approach, the following defect types were recognized as the most common defects that may occur in deck closure joints:

1. delamination

2. cracks

3. voids

4. corrosion of embedded steel.

Collectively, these four types of defects/damages represent, by type or feature, all expected types of damage and defects in closure joints.

\subsection{Quantitative Comparison among the Most Promising NDT Methods}

To substantiate the basic conclusions of the above analyses with quantitative measures, a statistical survey of the applicability of NDT methods to specific types of defects/damage was performed.

A total of 50 literature sources were reviewed and evaluated for this purpose. The defects considered for this evaluation as described above were delamination, cracks (includes debonding), voids, and corrosion of the embedded steel.

The criteria or measure considered for this evaluation was the number of citations of a specific method deemed applicable to a specific defect. In other words, to derive a quantitative measure for comparison among various NDT methods and their applicability to each defect type, results of the literature search were analyzed to find the number of sources that identified a method as being applicable to a defect type. Information for each defect type is summarized in Table 3. In this table, the first column lists the four groups of expected defects for closure joints. The second column of this table lists the NDT methods recognized as being promising for closure joints. Subsequently, the sources/references that have identified each NDT method for applicability to a certain type of defect are listed in the third column in a row corresponding to the NDT method and the row corresponding to the type of defect. $\mathrm{N}$ and $\mathrm{M}$ in the fourth and fifth columns of the table refer to the total number of sources (for each NDT method applicable to the type of defect) and the percentage of the number of sources in comparison with the total sources cited, respectively. 
Table 3. Statistical survey of applicability of NDT methods to defects in ABC closure joints [19-68].

\begin{tabular}{|c|c|c|c|c|}
\hline $\begin{array}{l}\text { Type of } \\
\text { Defect }\end{array}$ & & References & $\mathbf{N}$ & $\mathbf{M}$ \\
\hline \multirow{7}{*}{ Delamination } & IE & {$[20,26,27,29,30,40,41,43-45,48,53,55,56,61,62,68]$} & 17 & $34 \%$ \\
\hline & GPR & {$[19,20,22-27,29,31-35,38,40,43,45,46,48,50-53,55-57,59-66]$} & 35 & $70 \%$ \\
\hline & $\mathrm{UT}$ & {$[20,40,48,55,58,61,64,68]$} & 8 & $16 \%$ \\
\hline & IR & {$[22,26-30,33,41,42,48,51,53,54,59-61,63,65,67]$} & 19 & $38 \%$ \\
\hline & IRT & {$[21,40,48,51]$} & 4 & $8 \%$ \\
\hline & RT & [32] & 1 & $2 \%$ \\
\hline & MFL & - & 0 & $0 \%$ \\
\hline \multirow{7}{*}{ Corrosion } & IE & {$[26,56]$} & 2 & $4 \%$ \\
\hline & GPR & {$[19,20,24,26,27,31,34,37,38,44,45,48,55,62]$} & 14 & $28 \%$ \\
\hline & UT & {$[47,56]$} & 2 & $4 \%$ \\
\hline & IR & [27] & 1 & $2 \%$ \\
\hline & IRT & - & 0 & $0 \%$ \\
\hline & RT & - & 0 & $0 \%$ \\
\hline & MFL & [28] & 1 & $2 \%$ \\
\hline \multirow{7}{*}{ Crack } & IE & {$[27,29,47,48,55,61]$} & 6 & $12 \%$ \\
\hline & GPR & {$[19,34,35,52,55]$} & 5 & $10 \%$ \\
\hline & UT & {$[20,23,26,28,32,36,39,40,48,53,55,58,60,61,64]$} & 15 & $30 \%$ \\
\hline & IR & {$[20,28,29,47,48,61,65,67]$} & 8 & $16 \%$ \\
\hline & IRT & {$[47,48,51]$} & 3 & $6 \%$ \\
\hline & RT & {$[26,47]$} & 2 & $4 \%$ \\
\hline & MFL & [49] & 1 & $2 \%$ \\
\hline \multirow{7}{*}{ Void } & IE & {$[20,26,28,29,47,48,53,61,62]$} & 9 & $18 \%$ \\
\hline & GPR & {$[19,20,23,26,28,29,32,36,46,48,50,53,60,65]$} & 14 & $28 \%$ \\
\hline & UT & {$[20,23,26,39,40,53,61]$} & 7 & $14 \%$ \\
\hline & IR & {$[20,26,29,42,47,48,51,60]$} & 8 & $16 \%$ \\
\hline & IRT & {$[21,47,48,51]$} & 4 & $8 \%$ \\
\hline & RT & {$[26,32,47,53]$} & 4 & $8 \%$ \\
\hline & MFL & - & 0 & $0 \%$ \\
\hline
\end{tabular}

The results are also illustrated in Figures 6-9 for clarity. The charts clearly show the NDT method(s) that is (are) most appropriate for each damage type in closure joints, as denoted by the higher percentage(s). Each chart shows the results for one of the four common types or groups of damage or defects.

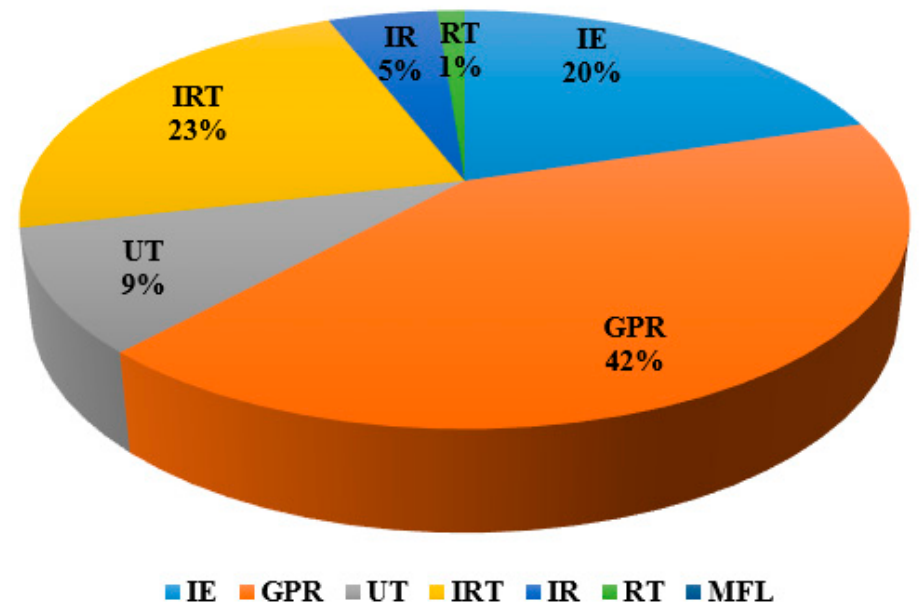

Figure 6. Statistical representation of NDT methods most applicable to detect delamination. 


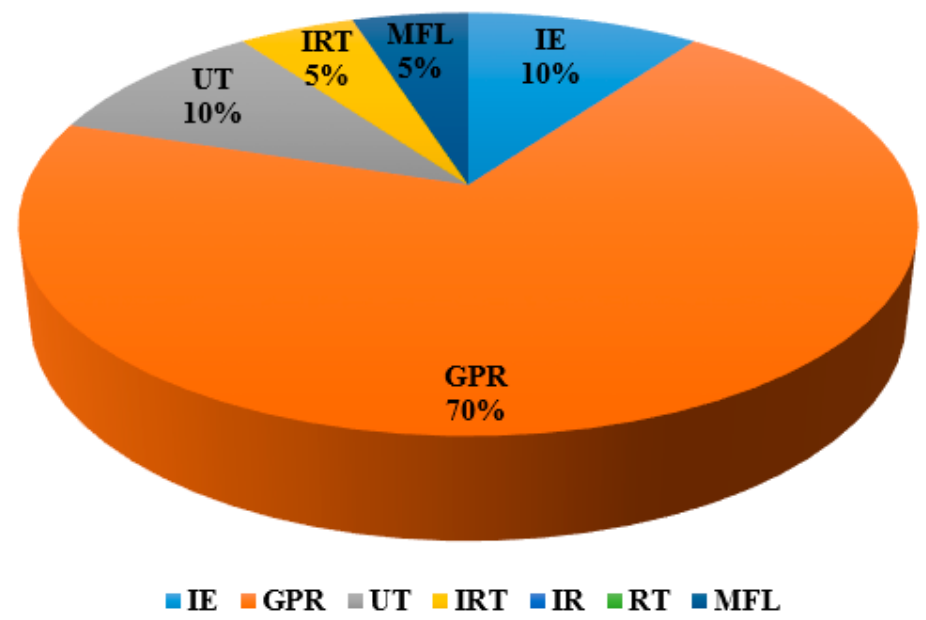

Figure 7. Statistical representation of NDT methods most applicable to detect corrosion.

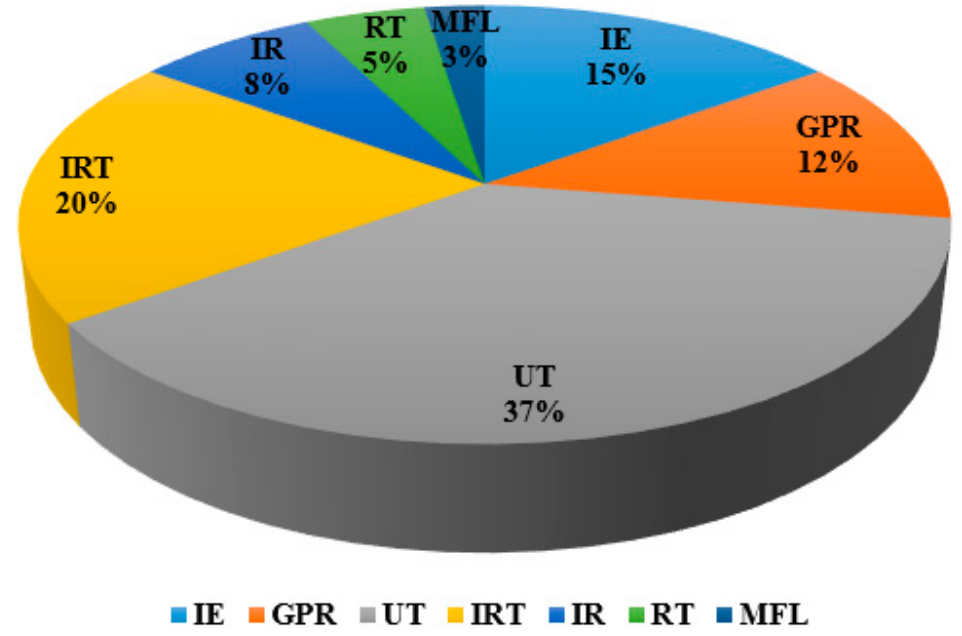

Figure 8. Statistical representation of NDT methods most applicable to detect cracks.

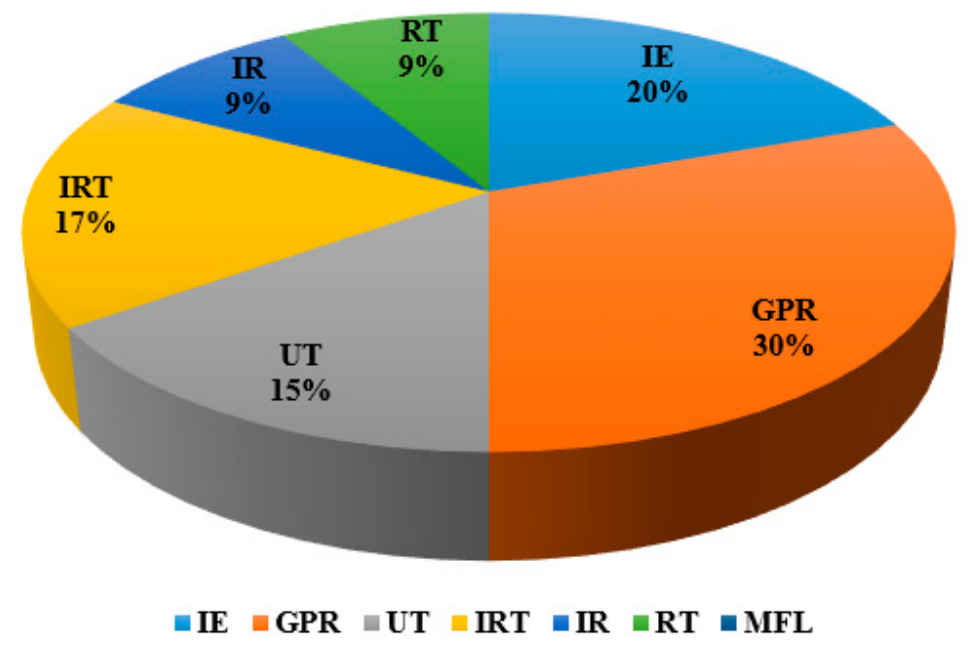

Figure 9. Statistical representation of NDT methods most applicable to detect voids.

The charts in Figures 6-9 can be used as a selection guide and allow bridge owners/operators to select the most-applicable NDT method for detecting each type of specific damage/defects. The results presented here attempt to establish a clear relationship between the expected damage/defects in each of the five distinctive types of closure joints and appropriate NDT methods. Along with future 
development of field procedures and reporting methods, the selection and decision-making aids developed in this study can be integrated into states' and national bridge health monitoring programs.

\section{Conclusions}

In Accelerated Bridge Construction ( $\mathrm{ABC}$ ), prefabricated bridge deck elements are connected to each other using "closure joints." Because of the cast-in-place nature of closure joints that are expected to go into service rapidly and problems observed for some types of closure joints, there have been some concerns about their long-term durability. The closure joints have presented themselves as the weak link in bridges built using high-quality manufactured prefabricated elements and systems. Therefore, for the health monitoring of $\mathrm{ABC}$ bridges, it has become important to first assure that the closure joints are free of defects immediately after construction, and that any damage can be detected during their service life to allow for timely remediation. Otherwise, the susceptibility of closure joint details to damage may question the entire notion of benefits from ABC. Non-destructive testing (NDT) methods offer valuable means for monitoring the health of closure joints. In this paper, a detailed investigation was presented on the evaluation of NDT methods that are applicable to specific defects related to various types of closure joints in $\mathrm{ABC}$. For this purpose, closure joints in bridge decks were categorized into five groups according to their composition and distinctive details, as well as their potential damage. Evaluation of the performance of the closure joints and general observations from bridge inspections pointed to a series of types of damage and their expected sequence for closure joints using a practical damage sequence tree (DST). Taking into account the specific characteristics of closure joint types and aided by the DST, the most likely causes for defects and types of damage were identified. Construction of a rational association between defects and their causes was undertaken in the form of damage etiology. The process determined that most of the defects related to the ABC closure joints can be caused by one or more of issues related to the material, design, workmanship, mechanical, and environmental factors. These factors were incorporated into a fault tree analysis (FTA), which is believed to be instrumental for the effective and accurate selection of NDT methods for the health monitoring of ABC bridges. As part of this study, a comprehensive literature search was performed to first identify the most promising NDT techniques and their respective capabilities for application to ABC closure joints. The results were then analyzed through a DST and FTA to construct a guidance framework that is capable of the practical identification of NDT methods that are most appropriate for the detection of specific defects associated with each type of closure joint. To substantiate the basic conclusions of these analyses with quantitative measures, a statistical survey of the applicability of NDT methods to specific types of defects and damage was performed. More than 50 papers and information sources were reviewed to obtain the information necessary for this analysis, mainly in the form of the number of citations for each method as being effective or applied to certain defects and damage types. The procedure and framework presented in this paper can be effectively and readily used by the bridge owners/operators and/or consultants as a guideline for connecting the capabilities of NDT methods to potential defects that are expected for closure joints, and for selecting the most appropriate method that best serves the purpose of the bridge health monitoring. The results of the study reported in this paper have been organized such that its outcomes would allow for future development of field procedures, reporting techniques, and suitability for integration into bridge health monitoring programs. Laboratory and field verification are being considered as future research to demonstrate the utility of the guideline developed as part of this study.

Author Contributions: Conceptualization, S.F. and A.M.; methodology, S.F. and A.M.; software, S.F. and A.M.; validation, S.F. and A.M.; formal analysis, S.F. and A.M.; investigation, S.F. and A.M.; resources, S.F. and A.M.; data curation, S.F. and A.M.; writing - original draft preparation, S.F. and A.M.; writing-review and editing, S.F. and A.M.; visualization, S.F. and A.M.; supervision, S.F. and A.M.; project administration, S.F. and A.M.; funding acquisition, S.F. and A.M. All authors have read and agree to the published version of the manuscript.

Funding: This paper is based on a project supported by the United States Department of Transportation (Grant No. DTRT13-G-UTC41) through the Accelerated Bridge Construction University Transportation Center (ABC-UTC). 
Acknowledgments: The comprehensive version of this research was presented in the ABC-UTC guideline entitled: "ABC-UTC Guide for: Selection of NDT Methods Application to Health Monitoring of ABC Closure Joints". The opinions, findings and conclusions expressed here are those of the author(s) and not necessarily of the sponsor.

Conflicts of Interest: The authors declare no conflict of interest.

\section{References}

1. Mehrabi, A.; Farhangdoust, S. ABC-UTC Guideline for: Selection of NDT Methods Application to Health Monitoring of $A B C$ Closure Joints; Accelerated Bridge Construction University Transportation Center: Miami, FL, USA, 2019.

2. Attanayake, U.; Aktan, H. First-generation ABC system, evolving design, and half a century of performance: Michigan side-by-side box-beam bridges. J. Perform. Constr. Facil. 2015, 29, 04014090. [CrossRef]

3. Terry, W. Iowa's Perspective on ABC. In Proceedings of the FHWA ABC Workshop 2009 International Bridge Conference, Seattle, WA, USA, 3 June 2009.

4. Mehrabi, A.B.; Farhangdoust, S. A Laser-Based Noncontact Vibration Technique for Health Monitoring of Structural Cables: Background, Success, and New Developments. Adv. Acoust. Vib. 2018, 2018, 8640674. [CrossRef]

5. Culmo, M.P. Connection Details for Prefabricated Bridge Elements and Systems; Federal Highway Administration: McLean, VA, USA, 2009.

6. Sutter, L.; Peterson, K.; Julio-Betancourt, G.; Hooton, D.; Dam, T.V.; Smith, K. The Deleterious Chemical Effects of Concentrated Deicing Solutions on Portland Cement Concrete; No. SD2002-01-F; South Dakota Department of Transportation, Office of Research: Pierre, SD, USA, 2008.

7. Gucunski, N.; Romero, F.; Kruschwitz, S.; Feldmann, R.; Parvardeh, H. Comprehensive Bridge Deck Deterioration Mapping of Nine Bridges by Nondestructive Evaluation Technologies; No. Project SPR-NDEB (90)-8H-00; Iowa Department of Transportation: Ames, IA, USA, 2011.

8. Utah Department of Transportation (UDOT) Research Division. Lessons Learned After Construction: Bridge County Road Over I-80; Project No. IBHF-80-4(90)160; Utah Department of Transportation (UDOT) Research Division: Taylorsville, UT, USA, October 2004.

9. Hopper, T.; Manafpour, A.; Warn, G.; Rajabipour, F.; Morian, D.; Jahangirnejad, S. Bridge Deck Cracking: Effects on In-Service Performance, Prevention, and Remediation; No. FHWA-PA-2015-006-120103; Pennsylvania Department of Transportation Bureau of Planning and Research: Harrisburg, PA, USA, 2015.

10. Aktan, H.; Attanayake, U.; Ulku, E. Condition Assessment and Methods of Abatement of Prestressed Concrete Box-Beam Deterioration-Phase II; Research Report RC-1527; Michigan Department of Transportation Construction and Technology Division: Washington, DC, USA, 2009.

11. Brown, M.; Sellers, G.; Folliard, K.; Fowler, D. Restrained Shrinkage Cracking of Concrete Bridge Decks: State-of-the-Art Review; Rep. FHWA/TX-0-4098-1.2001; The National Academies of Sciences Engineering Medicine: St. Paul, MN, USA, 2001.

12. E. \& D. MD. Prefabricated Bridge Replacement Report: i-215 East 3760 S. \& 3900 S; Project No. IBHF-215-9(110)2; E. \& D. MD: Salt Lake City, UT, USA, 2004.

13. Farhangdoust, S.; Mehrabi, A.B. NDT Inspection of Critical ABC Details to Assure Life Cycle Performance and Avoid Future Unforeseen Excessive Repairs. In Proceedings of the Structures Congress 2019 American Society of Civil Engineers, Orlando, FL, USA, 24-27 April 2019.

14. Farhangdoust, S.; Mehrabi, A.B.; Al Mosawi, S.F. NDT Methods Applicable to Health Monitoring of ABC Closure Joints. In Proceedings of the 27th Research Symposium-The American Society for Non-destructive Testing (ASNT), Orlando, FL, USA, 26-29 March 2018.

15. Rettner, D.L.; Fiegen, M.S.; Snyder, M.B.; MacDonald, K.A. Analysis of Bridge Deck Cracking Data a Review of Mechanisms, Analysis of MnDOT Bridge Construction Data, and Recommendation for Treatment and Prevention; Rep.MN/RC 2014-09; The National Academies of Sciences Engineering Medicine: St. Paul, MN, USA, 2014.

16. Azimi, G.; Rahimi, A.; Asgari, H.; Jin, X. Severity analysis for large truck rollover crashes using a random parameter ordered logit model. Accid. Anal. Prev. 2020, 135, 105355. [CrossRef] [PubMed]

17. Hasanian, M.; Choi, S.; Lissenden, C. Laser Ultrasonics for Remote Detection of Stress Corrosion Cracking in Harsh Environments. In Proceedings of the 27th ASNT Research Symposium, Orlando, FL, USA, 26 March 2018; pp. 106-115. 
18. Farhangdoust, S.; Mehrabi, A. Health Monitoring of Closure Joints in Accelerated Bridge Construction: A Review of Non-Destructive Testing Application. J. Adv. Concr. Technol. 2019, 17, 381-404. [CrossRef]

19. Sun, H.; Pashoutani, S.; Zhu, J. Nondestructive Evaluation of Concrete Bridge Decks with Automated Acoustic Scanning System and Ground Penetrating Radar. Sensors 2018, 18, 1955. [CrossRef]

20. Lin, S.; Meng, D.; Choi, H.; Shams, S.; Azari, H. Laboratory assessment of nine methods for nondestructive evaluation of concrete bridge decks with overlays. Constr. Build. Mater. 2018, 188, 966-982. [CrossRef]

21. Davis, A.G. The nondestructive impulse response test in North America: 1985-2001. NDT E Int. 2003, 36, 185-193. [CrossRef]

22. Washer, G.; Fenwick, R.; Bolleni, N.; Harper, J. Effects of environmental variables on infrared imaging of subsurface features of concrete bridges. Transp. Res. Rec. 2009, 2108, 107-114. [CrossRef]

23. Maierhofer, $\mathrm{C}$. Nondestructive evaluation of concrete infrastructure with ground penetrating radar. J. Mater. Civ. Eng. 2003, 15, 287-297. [CrossRef]

24. Tarussov, A.; Vandry, M.; De La Haza, A. Condition assessment of concrete structures using a new analysis method: Ground-penetrating radar computer-assisted visual interpretation. Constr. Build. Mater. 2013, 38, 1246-1254. [CrossRef]

25. Huston, D.; Hu, J.Q.; Maser, K.; Weedon, W.; Adam, C. GIMA ground penetrating radar system for monitoring concrete bridge decks. J. Appl. Geophys. 2000, 43, 139-146. [CrossRef]

26. No, T.C.S. Guidebook on Non-Destructive Testing of Concrete Structures; Training Course Series; International Atomic Energy Agency: Vienna, Austra, 2002.

27. Scott, M.; Rezaizadeh, A.; Delahaza, A.; Santos, C.G.; Moore, M.; Graybeal, B.; Washer, G. A comparison of nondestructive evaluation methods for bridge deck assessment. NDT E Int. 2003, 36, 245-255. [CrossRef]

28. Chase, S.B.; Washer, G. Nondestructive evaluation for bridge management in the next century. Public Roads 1997, 61, 16-25.

29. Yehia, S.; Abudayyeh, O.; Nabulsi, S.; Abdelqader, I. Detection of common defects in concrete bridge decks using nondestructive evaluation techniques. J. Bridge Eng. 2007, 12, 215-225. [CrossRef]

30. Oh, T.; Kee, S.H.; Arndt, R.W.; Popovics, J.S.; Zhu, J. Comparison of NDT methods for assessment of a concrete bridge deck. J. Eng. Mech. 2012, 139, 305-314. [CrossRef]

31. Sbartaï, Z.M.; Laurens, S.; Balayssac, J.P.; Arliguie, G.; Ballivy, G. Ability of the direct wave of radar ground-coupled antenna for NDT of concrete structures. NDT E Int. 2006, 39, 400-407. [CrossRef]

32. Büyüköztürk, O. Imaging of concrete structures. NDT E Int. 1998, 31, 233-243. [CrossRef]

33. Rhazi, J. NDT in civil engineering: The case of concrete bridge decks. CSNDT J. 2000, 21, 18-25.

34. Barnes, C.L.; Trottier, J.F.; Forgeron, D. Improved concrete bridge deck evaluation using GPR by accounting for signal depth-amplitude effects. NDT E Int. 2008, 41, 427-433. [CrossRef]

35. Alani, A.M.; Aboutalebi, M.; Kilic, G. Integrated health assessment strategy using NDT for reinforced concrete bridges. NDT E Int. 2014, 61, 80-94. [CrossRef]

36. Kohl, C.; Streicher, D. Results of reconstructed and fused NDT-data measured in the laboratory and on-site at bridges. Cem. Concr. Compos. 2006, 28, 402-413. [CrossRef]

37. Rhazi, J.; Dous, O.; Laurens, S. A new application of the GPR technique to reinforced concrete bridge decks. In Proceedings of the 4th Middle East NDT Conference and Exhibition, Manama, Bahrain, December 2007; pp. $2-5$.

38. Rhazi, J.; Dous, O.; Ballivy, G.; Laurens, S.; Balayssac, J.P. Non destructive health evaluation of concrete bridge decks by GPR and half cell potential techniques. In Proceedings of the International Symposium on Non-Destructive Testing in Civil Engineering, Berlin, Germany, 16-19 September 2003.

39. Maierhofer, C.; Zacher, G.; Kohl, C.; Wöstmann, J. Evaluation of radar and complementary echo methods for NDT of concrete elements. J. Nondestruct. Eval. 2008, 27, 47. [CrossRef]

40. Lim, M.K.; Cao, H. Combining multiple NDT methods to improve testing effectiveness. Constr. Build. Mater. 2013, 38, 1310-1315. [CrossRef]

41. Krause, M.; Mielentz, F.; Milman, B.; Müller, W.; Schmitz, V.; Wiggenhauser, H. Ultrasonic imaging of concrete members using an array system. NDT E Int. 2001, 34, 403-408. [CrossRef]

42. Abdel-Qader, I.; Yohali, S.; Abudayyeh, O.; Yehia, S. Segmentation of thermal images for non-destructive evaluation of bridge decks. NDT E Int. 2008, 41, 395-405. [CrossRef] 
43. Gucunski, N.; Romero, F.; Kruschwitz, S.; Feldmann, R.; Abu-Hawash, A.; Dunn, M. Multiple complementary nondestructive evaluation technologies for condition assessment of concrete bridge decks. Transp. Res. Rec. 2010, 2201, 34-44. [CrossRef]

44. Arndt, R.; Jalinoos, F. NDE for corrosion detection in reinforced concrete structures-a benchmark approach. In Proceedings of the Non-Destructive Testing in Civil Engineering (NDTCE'09), Nantes, France, 30 June-3 July 2009; p. 30.

45. Mehrabi, A.; Farhangdoust, S. NDT Methods Applicable to Health Monitoring of ABC Closure Joints; No. ABC-UTC-2013-C3-FIU04; Accelerated Bridge Construction University Transportation Center (ABC-UTC): Miami, FL, USA, 2019.

46. Bungey, J.H. Sub-surface radar testing of concrete: A review. Constr. Build. Mater. 2004, 18, 1-8. [CrossRef]

47. Akhtar, S. Review of nondestructive testing methods for condition monitoring of concrete structures. J. Constr. Eng. 2013, 2013. [CrossRef]

48. Rehman, S.K.U.; Ibrahim, Z.; Memon, S.A.; Jameel, M. Nondestructive test methods for concrete bridges: A review. Constr. Build. Mater. 2016, 107, 58-86. [CrossRef]

49. Krause, H.-J.; Wolf, W.; Glaas, W.; Zimmermann, E.; Faley, M.I.; Sawade, G.; Mattheus, R.; Neudert, G.; Gampe, U.; Krieger, J. SQUID array for magnetic inspection of prestressed concrete bridges. Physica C 2002, 368, 91-95. [CrossRef]

50. Belli, K.; Wadia-Fascetti, S.; Rappaport, C. Model based evaluation of bridge decks using ground penetrating radar. Comput. Aided Civ. Infrastruct. Eng. 2008, 23, 3-16. [CrossRef]

51. Bungey, J.H.; Grantham, M.G. Testing of Concrete in Structures; CRC Press: Boca Raton, FL, USA, 2014.

52. Alani, A.M.; Aboutalebi, M.; Kilic, G. Applications of ground penetrating radar (GPR) in bridge deck monitoring and assessment. J. Appl. Geophys. 2013, 97, 45-54. [CrossRef]

53. Zhu, J. Non-Contact NDT of Concrete Structures Using Air Coupled Sensors; Newmark Structural Engineering Laboratory, University of Illinois at Urbana-Champaign: Urbana, IL, USA, 2008.

54. Omar, T.; Nehdi, M.L. Remote sensing of concrete bridge decks using unmanned aerial vehicle infrared thermography. Autom. Constr. 2017, 83, 360-371. [CrossRef]

55. Gucunski, N.; Kee, S.H.; La, H.; Basily, B.; Maher, A.; Ghasemi, H. Implementation of a fully autonomous platform for assessment of concrete bridge decks RABIT. Struct. Congr. 2015, 2015, 367-378.

56. Gucunski, N.; Kee, S.; La, H.; Basily, B.; Maher, A. Delamination and concrete quality assessment of concrete bridge decks using a fully autonomous RABIT platform. Struct. Monit. Maint. 2015, 2, 19-34. [CrossRef]

57. Van der Wielen, A.; Courard, L.; Nguyen, F. Nondestructive detection of delaminations in concrete bridge decks. In Proceedings of the XIII Internarional Conference on Ground Penetrating Radar, Lecce, Italy, 21-25 June 2010; pp. 1-5.

58. Shokouhi, P.; Wolf, J.; Wiggenhauser, H. Detection of delamination in concrete bridge decks by joint amplitude and phase analysis of ultrasonic array measurements. J. Bridge Eng. 2013, 19, 04013005. [CrossRef]

59. Washer, G.A. Developments for the non-destructive evaluation of highway bridges in the USA. NDT E Int. 1998, 31, 245-249. [CrossRef]

60. Hearn, G.; Shim, H.S. Integration of bridge management systems and nondestructive evaluations. J. Infrastruct. Syst. 1998, 4, 49-55. [CrossRef]

61. Rens, K.L.; Nogueira, C.L.; Transue, D.J. Bridge management and nondestructive evaluation. J. Perform. Constr. Facil. 2005, 19, 3-16. [CrossRef]

62. Huston, D.; Cui, J.; Burns, D.; Hurley, D. Concrete bridge deck condition assessment with automated multisensor techniques. Struct. Infrastruct. Eng. 2011, 7, 613-623. [CrossRef]

63. Maser, K.R.; Roddis, W.K. Principles of thermography and radar for bridge deck assessment. J. Transp. Eng. 1990, 116, 583-601. [CrossRef]

64. Toutanji, H. Ultrasonic wave velocity signal interpretation of simulated concrete bridge decks. Mater. Struct. 2000, 33, 207. [CrossRef]

65. Vaghefi, K.; Oats, R.C.; Harris, D.K.; Ahlborn, T.T.M.; Brooks, C.N.; Endsley, K.A.; Roussi, C.; Shuchman, R.; Burns, J.W.; Dobson, R. Evaluation of commercially available remote sensors for highway bridge condition assessment. J. Bridge Eng. 2011, 17, 886-895. [CrossRef]

66. Xu, Y.; Turkan, Y. Bridge Inspection Using Bridge Information Modeling (BrIM) and Unmanned Aerial System (UAS). In Advances in Informatics and Computing in Civil and Construction Engineering; Springer: Cham, Switzerland, 2019; pp. 617-624. 
67. Chen, S.; Laefer, D.F.; Mangina, E.; Zolanvari, S.I.; Byrne, J. UAV Bridge Inspection through Evaluated 3D Reconstructions. J. Bridge Eng. 2019, 24, 05019001. [CrossRef]

68. Bogue, R. Applications of robotics in test and inspection. Ind. Robot 2018, 45, 169-174. [CrossRef] 